American Journal of Pharmaceutical Education 2013; 77 (7) Article 138.

\title{
ADDRESSES
}

\section{Tables of Influence}

\author{
J. Lyle Bootman, PhD
}

2012-2013 President, American Association of Colleges of Pharmacy

Address at the Opening General Session of the American Association of Colleges of Pharmacy Annual Meeting in Chicago, IL, on July 14, 2013.

Colleagues, it has been an amazing year for the American Association of Colleges of Pharmacy (AACP) and such an honor for me, personally, to serve as your president. A year ago I outlined an ambitious agenda, challenging AACP and our members to get to the right tables of influence in this era of remarkable change in healthcare, education, and research.

In each sector there is a need for pharmacy educators to make contributions as part of collaborative teams to improve the value equation in discovery, learning, and patient care. As I knew you would, the academy responded in innumerable ways with advocacy and action at the local, state, national, and international levels. The award recipients we just recognized are among the stellar examples I can cite.

Our members are providing great leadership in establishing new models of practice and creating the evidence that, when pharmacists have opportunities to add value in medication management and participate on interprofessional teams, the triple aim of better care, better health, and lower costs can be achieved. Kudos to a number of our schools that are directly involved in the development of pharmacy practice models in Accountable Care Organizations and medical homes.

At least 8 schools have innovations awards from the Centers for Medicare and Medicaid Services (CMS) that are examining how healthcare and value can be enhanced through more robust medication management services delivered by pharmacists. We know that CMS is studying such work very carefully, and this will influence ongoing efforts to expand access to more effective and efficient health services.

Preparing our graduates to practice in patientcentered teams is a high priority. I believe your recognition of this helps to explain the success of the 3 interprofessional faculty development institutes that our association has co-convened with our Interprofessional Education Collaborative partners. Each institute has quickly sold out, and there remains a list of almost 200 faculty members awaiting the next programs. We anticipate convening at least 3 more interprofessional education institutes between now and next year's annual meeting. In August, registration will begin for the next program in early October.

Our standing committees were also especially productive this year, and I highly recommend that you read each report. AACP recognizes that all the work to improve healthcare and education depends on effective partnerships.

This year the Professional Affairs Committee intensely studied the important relationships between our schools, state pharmacy associations, and state boards of pharmacy. My thanks to Linda Garrelts MacLean, from Washington State University, and the committee for their honest and hard-hitting analysis of this triad relationship.

Quoting from their report, "We cannot forget how interconnected we are, be it the work of colleges who educate future pharmacists and provide the scholarship and research to advance science and improve practice, or our boards' work in advancing and protecting public health, or the work of state associations in advocating and leading the advancement of professional practice. Our individual organization's success will not occur without supporting and valuing the other two groups and playing a role in advancing their successes. In the words of Helen Keller: 'Alone we can do so little; together we can do so much."”

The report includes a number of examples of the effective collaboration models that can guide the strengthening of this triad relationship with all of its implications for our progressive agenda.

The Research and Graduate Affairs Committee chaired by Bob Blouin, University of North Carolina at Chapel Hill, also recognized that strong science will increasingly depend on collaborative research teams and extraordinary leaders. His committee assisted Vincent Lau, AACP Chief Science Officer, with the design of our new Academic Research Fellows Program. Sixteen fellows from diverse sectors of science will embark on a year-long journey beginning in September. They will interact with research leaders and funding agencies to increase their depth and breadth of knowledge, equipping 


\section{American Journal of Pharmaceutical Education 2013; 77 (7) Article 138.}

them to step up and become the next generation of leaders in team science. I will be especially pleased to welcome them to Tucson, where the second of their 4 sessions will take place.

Speaking of leaders, last night we celebrated the commencement of the ninth cohort of our Academic Leadership Fellows Program. In a few short weeks, the tenth cohort will begin their year of learning and refining their strengths for leading change in academic pharmacy. We have had nearly 300 Academic Leadership Fellows Program participants over this decade, and I have extraordinary confidence that these graduates are primed to provide the academy, AACP, and the profession with the leadership we need for these uncertain - and in many ways, challenging - times.

My thanks also go to Marie Smith from the University of Connecticut, and Will Lang, AACP staff liaison to the Advocacy Committee. This group used a different and highly effective approach to their work in advancing AACP's advocacy agenda this year.

Four priority issues were identified, and each issue leader facilitated a work group of member volunteers recruited from the Council of Deans and Council of Faculties in the development of advocacy resources on each issue. Today we have issue briefs, background resources, and opinion pieces appropriate for the consumer and health policy audiences on these top-of-mind issues in pharmacy education and practice. These support our ongoing advocacy efforts and collaboration with many other pharmacy, healthcare, and education associations who believe deeply that state and federal resources and payment policies must align with the goals of making the very best use of our graduates' knowledge and abilities.

We have 2 critical questions before us: What must the graduate of the future know as society's medicationuse specialist? And how best do they apply what they know to impact the outcomes of patients? Addressing these questions for the profession and society has been the work of the Center for the Advancement of Pharmacy Education (CAPE) Outcomes Panel, chaired by Melissa Medina. Perhaps no volunteer group in AACP history has ever worked as hard as Melissa and the panel. It is important to note that key contributors on the panel include representatives nominated from our practitioner colleague organizations around the Joint Commission of Pharmacy Practitioners table.

AACP is a very volunteer-driven association, with incalculable hours of time and talent invested by individuals in our special interest groups, sections, and councils. Section and council leaders also serve as members of the board of directors and strategic planning committee, ensuring that the needs of pharmacy faculty members and academic administrators are always in focus and part of the evaluation of important new member services. My thanks to all of you for these efforts.

The AACP Argus Commission is unique among all of our volunteers as it is the committee comprised of the past 5 AACP presidents. Each year the president identifies one of the big-picture areas worthy of study and assigns it to this thoughtful group of experienced leaders. They never disappoint us in their insights and bold interpretation of trends in issues in healthcare and education.

This year is no exception. I asked the Argus Commission, chaired by Cynthia Raehl, to examine the game changers in education, healthcare, science, and society.

They drew upon rich literature-mostly, but not exclusively, in the form of recent books - and identified forces of change at play that most certainly will impact pharmacy education. The higher education literature is overflowing with analyses and promotions of new models of teaching and learning, including massive open online courses - flipped classrooms with blended learning that tries to match learner needs and styles with the resources and style of learning facilitation.

At the AACP Leadership Retreat in March, our Section and Board leaders spent time learning about how technology has and will increasingly change models of education. The result of that session was the development of a video where leaders proposed how AACP can and should assist our members in incorporating these learning strategies into the work of faculty members and students.

Technology and the analysis of big data combine to change virtually every part of our world, including the delivery of healthcare services, our research, and our approach to managing the creative people in our organizations. The Argus Commission has presented the AACP Board of Directors with some far-reaching and provocative recommendations for future work in this new digital era.

Beyond the committee initiatives, the Association made many great additional strides. They are all documented in the 2013 AACP Annual Report, which is now available online.

I am extremely pleased with the progress that our Association has made during the past year, and I feel confident that all of you will benefit from these initiatives. I want to thank all of our volunteer leaders as well as Lucinda Maine and all of the AACP staff for your extraordinary effort and energy in making so many ideas a reality. 